\title{
Design, Synthesis, and Molecular Docking of 1-(1-(4-Chlorophenyl)-2-(phenylsulfonyl)ethylidene)-2- phenylhydrazine as Potent Nonazole Anticandidal Agent
}

\author{
Hazem A. Ghabbour, ${ }^{1}$ Maha M. Qabeel, ${ }^{2}$ Wagdy M. Eldehna, ${ }^{3}$ \\ Abdullah Al-Dhfyan, ${ }^{4}$ and Hatem A. Abdel-Aziz ${ }^{1,5}$ \\ ${ }^{1}$ Department of Pharmaceutical Chemistry, College of Pharmacy, King Saud University, P.O. Box 2457, Riyadh 11451, Saudi Arabia \\ ${ }^{2}$ Department of Clinical Microbiology and Immunology, College of Medicine, Mansoura University, Mansoura 35516, Egypt \\ ${ }^{3}$ Department of Pharmaceutical Chemistry, College of Pharmacy, Egyptian Russian University, P.O. Box 11829, Badr City, Cairo, Egypt \\ ${ }^{4}$ Stem Cell and Tissue Re-Engineering Program, Research Center, King Faisal Specialist Hospital and Research Center, \\ P.O. Box 3354, MBC 03, Riyadh 11211, Saudi Arabia \\ ${ }^{5}$ Department of Applied Organic Chemistry, National Research Center, Dokki, Cairo 12622, Egypt
}

Correspondence should be addressed to Hazem A. Ghabbour; ghabbourh@yahoo.com and Hatem A. Abdel-Aziz; hatem_741@yahoo.com

Received 18 October 2014; Revised 14 December 2014; Accepted 14 December 2014; Published 31 December 2014

Academic Editor: Tanaji Talele

Copyright @ 2014 Hazem A. Ghabbour et al. This is an open access article distributed under the Creative Commons Attribution License, which permits unrestricted use, distribution, and reproduction in any medium, provided the original work is properly cited.

1-(1-(4-Chlorophenyl)-2-(phenylsulfonyl)ethylidene)-2-phenylhydrazine (13) was designed and synthesized as potential nonazole anticandidal agent and precisely characterized by IR, ${ }^{1} \mathrm{H}$ NMR, ${ }^{13} \mathrm{C}$ NMR, and ESI-MS. The anti-Candida activity of 13 was evaluated against four Candida species (C. albicans, C. krusei, C. parapsilosis, and C. glabrata). Compound 13 displayed good anticandidal activities ( $\mathrm{MIC}=0.39,0.195,0.39$, and $1.56 \mu \mathrm{mol} / \mathrm{mL}$, resp.) in comparison with that of the standard drug fluconazole $(\mathrm{MIC}=0.195$, inactive, 1.56 , and $1.56 \mu \mathrm{mol} / \mathrm{mL}$, resp.) against C. albicans, C. krusei, C. parapsilosis, and C. glabrata, respectively. A molecular modeling of the newly synthesized compound $\mathbf{1 3}$ was built in order to investigate its mode of action towards the prospective target cytochrome P450-dependent enzyme lanosterol 14 $\alpha$-demethylase (PDB-code: 1EA1). The docking results showed a similar binding interaction of $\mathbf{1 3}$ and fluconazole at the active site of CYT P450 14 $\alpha$-sterol demethylase. Furthermore, compound 13 showed no cytotoxicity against normal human breast cell line MCF10A.

\section{Introduction}

In the current medical era, human fungal infections have stood out as an important clinical threat, with serious associated morbidity and mortality [1]. The human immunodeficiency virus (HIV) epidemic, stem cell transplantation, and modern progression in the fields of solid organ transplantation coupled with the advent of novel immunosuppressive drugs have collectively resulted in dramatic increase in the incidence and diversity of human fungal infections including those caused by Candida, Aspergillus, and Cryptococcus species [2].

In the last few decades, Candida has emerged as one of the most prevalent fungal pathogens, causing both mucosal candidiasis and invasive candidemia, although it is a part of the microbiota of gastrointestinal and urogenital tracts, skin, and mouth in healthy individuals [3]. Many endogenous and exogenous predisposing factors such as immunological disorders, immoderate administration of antimicrobial agents, and prolonged use of invasive catheters may result in impaired 


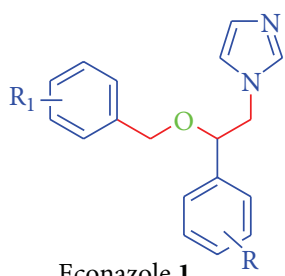

$\mathrm{R}=2,4-\mathrm{di}-\mathrm{Cl}, \mathrm{R}_{1}=4-\mathrm{Cl}$

Miconazole 2

$\mathrm{R}=\mathrm{R}_{1}=2,4$-di-C

Isoconazole 3

$\mathrm{R}=2,4-$ di- $\mathrm{Cl}, \mathrm{R}_{1}=2,6$-di- $\mathrm{Cl}$

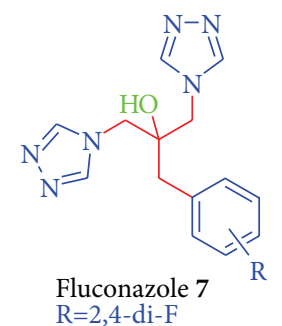

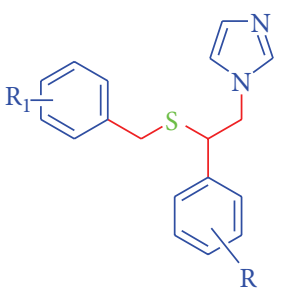

Sulconazole 4 $\mathrm{R}=4-\mathrm{Cl}, \mathrm{R}_{1}=2,4-\mathrm{di}-\mathrm{Cl}$

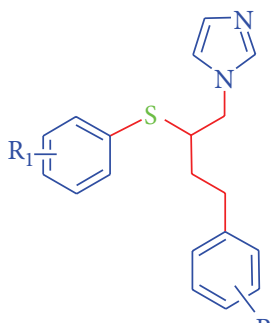

Butoconazole $5 \mathrm{R}$

$\mathrm{R}=4-\mathrm{Cl}, \mathrm{R}_{1}=2,6$-di-Cl

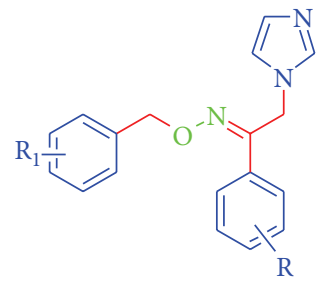

Oxiconazole 6

$\mathrm{R}=\mathrm{R}_{1}=2,4-$ di- $\mathrm{Cl}$
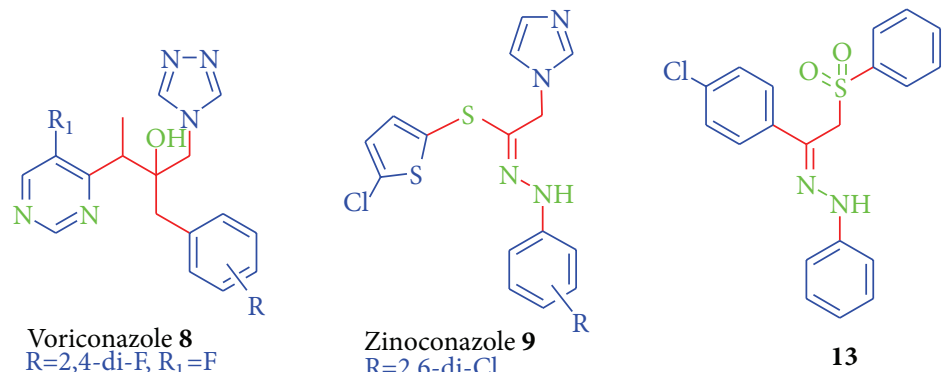

13

The title compound

FIgURE 1: Structures of antifungal drugs 1-9 and the title compound $\mathbf{1 3 .}$

host defence against Candida spp. and, subsequently, Candida become pathogenic and disseminate into the bloodstream to infect different organs [4].

According to the mode of action, there are main six classes of antifungal agents: fungal ergosterol synthesis inhibitors (azoles: ketoconazole, fluconazole, itraconazole, voriconazole, and posaconazole), ergosterol disruptors (polyenes antibiotics: amphotericin B and nystatin), squalene epoxidase inhibitors (terbinafine), glucan synthesis inhibitors (echinocandins, caspofungin, and micafungin), nucleic acid synthesis inhibitors (5-fluorocytosine), and chitin synthesis inhibitors (Nikkomycin and Polyoxins) [5-10].

The azole antifungals are the mainstay of therapy usually used to treat different Candida infections such as oropharyngeal and esophageal candidiasis, vulvovaginal candidiasis, candidemia, and disseminated candidiasis [11]. Azoles exert antifungal activity through inhibition of the fungal cytochrome P450-dependent $14 \alpha$-lanosterol demethylase through the binding of the N3-atom of the azole moiety to the sixth coordination of heme iron atom of the porphyrin in the substrate binding site of the enzyme [12]. Due to the fungistatic action of azoles on Candida spp., cells repetitively exposed to these antifungals adapt to the drug pressure and eventually become azole resistant [13].

On the other hand, azole antifungal agents showed fatal hepatotoxicity [14-16]. This side effect may be attributable to the imperfect specificity toward fungal enzyme where CYP51 is a member of the cytochrome P450 superfamily, which exists not only in fungi but in mammals $[17,18]$. The limited success of azoles, due to severe resistance and fatal hepatotoxicity, has resulted in an urgent need to give much attention to update and modify drug leads from the point of view of medicinal chemistry and drug design to fulfill safe and more potent antifungals.
Concerning the SAR of azoles antifungals, the azole ring has been evidenced to be one of the most important pharmacophores for the activity; also, it is a key toxicophore for the hepatotoxicity of azole antifungal drugs due to the coordination binding of its nitrogen atom to the iron atom of heme $[19,20]$. All of these findings inspired us to design and prepare novel nonazole lead compound with different structural pharmacophores hoping to obtain potent antifungal agent and separate the antifungal activity from toxicity.

Figure 1 summarized the main structural features of a series of azoles antifungals such as imidazoles 1-6 and triazole drugs $\mathbf{7}$ and $\mathbf{8}$ in addition to zinoconazole $\mathbf{9}$ (Figure 1). In the present study, the well-known azole antifungals $[21,22]$ were chosen as lead compounds for development of new nonazole scaffold. Firstly, the heteroaryl rings were replaced with a phenyl ring. Since the anticandidal activity of hydrazones was extensively reported [23-25], we decided to retain the phenylhydrazine moiety of zinoconazole $\mathbf{9}$.

Finally, in the present work, utilization of sulfone group was performed depending on the reported antimicrobial activity of sulfones [26-28] and due to the incorporation of sulfur in some azole antifungals such as sulconazole $\mathbf{4}$ and butoconazole 5 in addition to the incorporation of oxygen in ether functions of econazole $\mathbf{1}$, miconazole $\mathbf{2}$, isoconazole $\mathbf{3}$, and hydroxyl group of fluconazole 7 and voriconazole 8 .

In view of the facts mentioned above and as part of our ongoing effort to prepare biologically active agents [29$36]$, herein we present the design, synthesis, and preliminary biological evaluation of 1-(1-(4-chlorophenyl)-2-(phenylsulfonyl)ethylidene)-2-phenylhydrazine (13) as potent antifungal agent based on a novel nonazole scaffold. The mode of action of compound $\mathbf{1 3}$ to the potential receptor cytochrome P450 14 $\alpha$-sterol demethylase was investigated by molecular docking. 


\section{Experimental}

\subsection{Chemistry}

2.1.1. General. Melting points were determined on a Gallenkamp melting point apparatus and are uncorrected. Infrared (IR) spectra were recorded as $\mathrm{KBr}$ disks using the Perkin Elmer FT-IR Spectrum BX apparatus. NMR spectra were scanned in DMSO- $d_{6}$ on a Brucker NMR spectrometer operating at $500 \mathrm{MHz}$ for ${ }^{1} \mathrm{H}$ and $125 \mathrm{MHz}$ for ${ }^{13} \mathrm{C}$. Chemical shifts are expressed in $\delta$-values (ppm) relative to TMS as an internal standard. Coupling constants $(J)$ are expressed in $\mathrm{Hz}$. $\mathrm{D}_{2} \mathrm{O}$ was added to confirm the exchangeable protons. Mass spectra were measured on an Agilent Triple Quadrupole 6410 QQQ LC/MS equipped with an ESI (electrospray ionization) source.

2.1.2. Synthesis of 1-(4-Chlorophenyl)-2-(phenylsulfonyl)ethan1-one (12). This compound was prepared according to the reported method [37]. To a solution of 2-bromo-1-(4chlorophenyl)ethan-1-one (10) $(10 \mathrm{mmol})$ in absolute ethanol $(50 \mathrm{~mL})$, sodium benzenesulfinate (11) $(12 \mathrm{mmol})$ was added. The mixture was refluxed for $3 \mathrm{~h}$ and then left to cool. The reaction mixture was poured into cold water and the solid product filtered off, washed with water, dried, and finally recrystallized from EtOH to afford compound 12.

2.1.3. Synthesis of 1-(1-(4-Chlorophenyl)-2-(phenylsulfonyl)ethylidene)-2-phenylhydrazine (13). A mixture of the sulfone $\mathbf{1 2}$ $(1 \mathrm{mmol})$ and phenyl hydrazine $(1 \mathrm{mmol})$ in ethanol $(30 \mathrm{~mL})$ and acetic acid $(0.5 \mathrm{~mL})$ was added. The reaction mixture was stirred for $6 \mathrm{~h}$. The precipitated product was filtered off, washed with ethanol, and dried. Recrystallization from ethanol to afford the corresponding hydrazone 13 in $72 \%$ : m.p. $160-162^{\circ} \mathrm{C}$; IR $\nu 3341(\mathrm{NH}) \mathrm{cm}^{-1} ;{ }^{1} \mathrm{H}$ NMR $\left(\mathrm{DSMO}-d_{6}\right) \delta$ $5.17\left(\mathrm{~s}, 2 \mathrm{H}, \mathrm{CH}_{2}\right), 6.82-6.85(\mathrm{~m}, 1 \mathrm{H}, \mathrm{ArH}), 7.12(\mathrm{~d}, J=7.5 \mathrm{~Hz}$, $2 \mathrm{H}, \operatorname{ArH}), 7.23-7.26(\mathrm{~m}, 2 \mathrm{H}, \mathrm{ArH}), 7.32(\mathrm{~d}, J=8 \mathrm{~Hz}, 2 \mathrm{H}$, ArH), 7.53-7.56 (m, 2H, ArH), 7.59-7.63 (m, 1H, ArH), 7.71 (d, $J=8.5 \mathrm{~Hz}, 2 \mathrm{H}, \mathrm{ArH}), 9.81\left(\mathrm{~s}, \mathrm{D}_{2} \mathrm{O}\right.$ exchangeable, $\left.1 \mathrm{H}, \mathrm{NH}\right)$; ${ }^{13} \mathrm{C}$ NMR (DSMO- $d_{6}$ ) $\delta 51.54,113.00,120.06,127.26,127.88$, $128.12,128.93,128.97,131.88,133.93,136.50,139.26,144.46$; MS (ESI) $m / z 384.7[\mathrm{M}]^{+}$.

2.1.4. Synthesis of Compounds $14 \boldsymbol{a}-\boldsymbol{d}, \mathbf{1 5 a}, \boldsymbol{b}$, and $\mathbf{1 6} \boldsymbol{a}, \boldsymbol{b}$. These compounds were synthesized recently in a previous study [29].

2.2. Antifungal Activity. In this study we used four reference strains Candida albicans ATCC 90029, Candida parapsilosis ATCC 22019, Candida krusei ATCC 14247, and Candida glabrata ATCC 15126. Antifungal activity of the synthesized compounds was determined by the agar well diffusion method [38].

A $1 \times 10^{6} \mathrm{CFUs} / \mathrm{mL}$ yeast suspension was prepared for each isolate in phosphate-buffered saline (PBS) and MuellerHinton agar plates were inoculated automatically with a Spiral plater (Autoplate 4000; Spiral Biotech, Inc., Bethesda, $\mathrm{MD}$, USA). Subsequently, equidistant $(1 \mathrm{~cm}$ diameter) holes were made using sterile cork borer in the agar. Holes were filled with $100 \mu \mathrm{L}$ of the tested compound at concentration (100 $\mu \mathrm{mol}$ dissolved in $1 \mathrm{~mL}$ DMSO). $25 \mu \mathrm{g}$ fluconazole and solvent were included as positive and negative controls, respectively. The plates were incubated for $24 \mathrm{~h}$ at $37^{\circ} \mathrm{C}$. Afterwards, the antimicrobial activity of each newly synthesized compound was evaluated by measuring the inhibition zone diameters. The experiment was repeated on three separate occasions and the average zone of inhibition was calculated.

2.3. Minimal Inhibitory Concentration. The microdilution method was performed as described by Irobi et al. [39], with 96-well, round-bottom microtiter plates using RPMI 1640 medium (Life Technologies, New York, NY, USA) and 2\% glucose in MOPS buffered to $\mathrm{pH}$ 7. Dimethyl sulphoxide (DMSO) was used as solvent for the synthetic compounds, starting with $100 \mu \mathrm{mol}$ concentration of all compounds dissolved in $1 \mathrm{~mL} \mathrm{DMSO}$ and then reduced by successive twofold dilutions of stock solution using a calibrated micropipette. The final solutions concentrations were 100, 50, 25, 12.5, 6.25, $3.12,1.56,0.78,0.39$, and $0.195 \mu \mathrm{mol} / \mathrm{mL}$. The stock solutions of the synthetic compounds were dispersed in the assay medium to obtain appropriate concentrations in wells 1-10 in each row; drug-free medium was dispensed in wells 11 and 12. Fluconazole is used as reference drug. Sabouraud dextrose agar was used to culture yeast strains. The inoculums of microorganisms were prepared from cultures and were adjusted to $0.5 \mathrm{McFarland}$ standard; the suspensions were further diluted in RPMI 1640 medium to yield an inoculum concentration of approximately $10^{4} \mathrm{CFU} / \mathrm{mL}$. The inoculated plates were incubated for $48 \mathrm{~h}$ at $35^{\circ} \mathrm{C}$. Triplicate tests were performed and the average was taken as final reading. The MIC endpoint was defined as the lowest drug concentration exhibiting $100 \%$ inhibition of growth compared with the control well [40]. According to CLSI criteria 100\% growth inhibition is defined as clear wells. Therefore, the readings at MIC value were similar to the negative control without Candida. The MIC of fluconazole was determined for each species in parallel as a control, and antibiotic-free solvent was included as a negative control.

2.4. Molecular Docking. The crystal structure of cytochrome P450 14 $\alpha$-sterol demethylase (Cyp51) from Mycobacterium tuberculosis in complex with fluconazole (PDB 1EA1) was provided from Brookhaven protein data bank (PDB; http://www .rcsb.org/pdb) and loaded to Molegro Virtual Docker (MVD 2013.6.0.0 [win32]) program, fully functional free trial version with time limiting license [41] The nonbonded oxygen atoms of water, present in the crystal structure, was removed. ChemBio3D Ultra 10 [42] was used to draw the 3D structures of different ligands. Ligands were further preoptimized using free version of Marvinsketch 4.1.13 from Chemaxon Ltd [43] with MM force field and saved in Tripos mol2 file format. MolDock score functions were used with a $0.3 \AA$ grid resolution. The binding sites were defined to any residues with $10 \AA$ distant from the cocrystallized fluconazole in the complex crystal structure of the enzyme [44].

2.5. Apoptotic Evaluation for Compound 13. Apoptotic effect of compound $\mathbf{1 3}$ against noncancerous human breast 

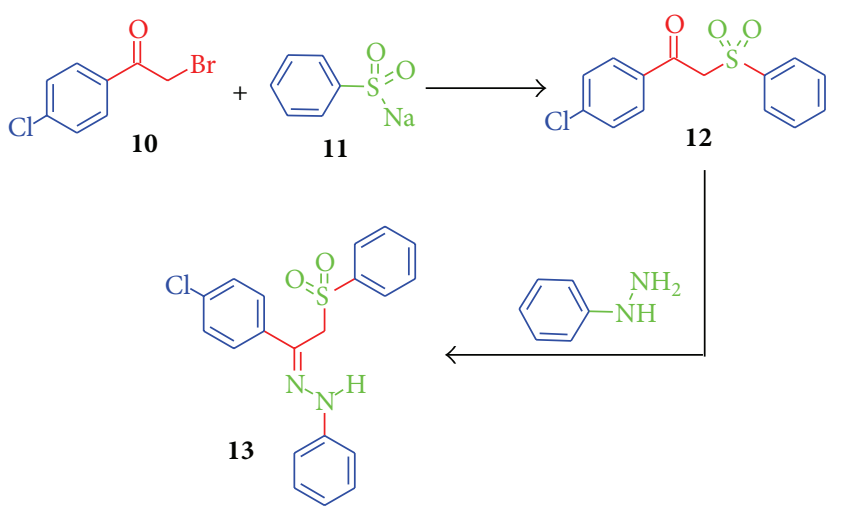

Scheme 1: Synthetic pathway of the title compound 13.

epithelial cell line MCF10A by measurement of annexin-V binding by flow cytometry was performed according to the reported method with minor modification [45].

\section{Results and Discussion}

3.1. Chemistry. 1-(4-Chlorophenyl)-2-(phenylsulfonyl)ethan-1-one (12) was synthesized by the reaction of 2-bromo-1(4-chlorophenyl)ethan-1-one (10) with sodium benzenesulfinate (11) (Scheme 1) [37]. Sulfone 12 was reacted with phenylhydrazine in ethanol at ambient temperature to afford the title compound $\mathbf{1 3}$ (Scheme 1). The IR spectrum of compound $\mathbf{1 3}$ revealed the appearance of absorption band of hydrazone $\mathrm{NH}$ at $3341 \mathrm{~cm}^{-1}$. The ${ }^{1} \mathrm{H}$ NMR of hydrazone 13 exhibited the signal of the $\mathrm{NH}$ group which appeared at $\delta$ 9.81 and the signal of $\mathrm{CH}_{2}$ protons appeared as singlet at $\delta$ 5.17 whereas its ${ }^{13} \mathrm{C}$ NMR revealed the signal of $\mathrm{CH}_{2}$ carbon at $\delta$ 51.54. The MS (ESI) analysis of $\mathbf{1 3}$ showed a peak at $m / z=384.7[\mathrm{M}]^{+}$.

In a previous study published recently, we synthesized compounds 14a-d, 15a, b, and 16a, b (Scheme 2) investigated here [29].

3.2. Antifungal Activity. Compounds 14a-d, 15a, b, and 16a, b [29] and the newly synthesized compound 13 were evaluated in vitro for their antifungal activity, by inhibition zone technique, using four Candida species (C. albicans, C. krusei, C. parapsilosis, and C. glabrata). The mean values of the inhibition zone diameter obtained for compound 13 suggest that compound 13 possesses significant antifungal activity against C. albicans, C. krusei, and C. parapsilosis (Table 1).

3.3. Minimum Inhibitory Concentration (MIC). Thereafter, minimum inhibitory concentration (MIC) of the compound 13 is evaluated in vitro using the twofold serial dilution technique. The lowest concentration showing no growth was chosen as the MIC. The results of minimum inhibitory concentration were displayed in Table 2.

The antifungal activity of $\mathbf{1 3}$ was compared with that of fluconazole, a standard antifungal drug. Investigations of the antifungal activity against C. krusei and C. parapsilosis indicated that they were the most sensitive species to the
TABLE 1: Antifungal activity of compounds 13-16 in mean inhibition diameters $(\mathrm{mm})$.

\begin{tabular}{lcccc}
\hline Compounds & C. albicans & C. krusei & C. parapsilosis & C. glabrata \\
\hline $\mathbf{1 3}$ & 33 & 39 & 35 & 22 \\
$\mathbf{1 4 a}$ & - & - & - & - \\
$\mathbf{1 4 b}$ & - & - & - & - \\
$\mathbf{1 4 c}$ & 14 & 11 & 18 & 12 \\
$\mathbf{1 4 d}$ & - & - & - & - \\
$\mathbf{1 5 a}$ & - & - & - & - \\
$\mathbf{1 5 b}$ & - & - & - & - \\
$\mathbf{1 6 a}$ & - & - & - & - \\
16b & - & - & - & - \\
Fluconazole & 29 & - & 27 & 23 \\
\hline
\end{tabular}

TABLE 2: Minimum inhibitory concentration (MIC) in $\mu \mathrm{mol} / \mathrm{mL}$ of 13.

\begin{tabular}{lcccc}
\hline Compound & C. albicans & C. krusei & C. parapsilosis & C. glabrata \\
\hline $\mathbf{1 3}$ & 0.39 & 0.195 & 0.39 & 1.56 \\
Fluconazole & 0.195 & - & 1.56 & 1.56 \\
\hline
\end{tabular}

influence of the compound $\mathbf{1 3}$ with MIC values of 0.195 and $0.39 \mu \mathrm{mol} / \mathrm{mL}$, respectively. Also, compound 13 almost was equipotent as fluconazole against C. glabrata $(\mathrm{MIC}=$ $1.56 \mu \mathrm{mol} / \mathrm{mL})$. On the other hand, compound 13 was 2 -fold less active than fluconazole against $C$. albicans with MIC value of $0.39 \mu \mathrm{mol} / \mathrm{mL}$.

3.4. Structure Activity Relationship for Compound 13. From the SAR point of view, the $N$-phenyl ring and hydrazone function of $\mathbf{1 3}$ is necessary for its activity. The activity of compound $\mathbf{1 3}$ may be due to the presence of three electron clouds of aryl groups with similar distribution with those of fluconazole (two triazole moieties and benzene ring).

3.5. Molecular Docking Study for Compound 13. Docking study was performed for $\mathbf{1 3}$ in order to investigate the possible interactions with cytochrome P450 14 $\alpha$-sterol demethylase from Mycobacterium tuberculosis (Mycobacterium P450 $\mathrm{DM})$. The crystallographic structure of the complex between cytochrome P450 14 $\alpha$-sterol demethylase from Mycobacterium tuberculosis (Mycobacterium P450 DM) and fluconazole (ID 1EA1) was used for the docking study [46].

Figure 2(a) shows the docked reference drug fluconazole in the active site of the enzyme for validation of our docking protocol. Azole ring is positioned almost perpendicular to the porphyrin plane (cofactor) where the nitrogen of azole ring coordinated to the heme iron. The distance between nitrogen atom of azole ring in fluconazole and heme ring was $2.34 \AA$. Fluconazole revealed a MolDock score of -161.29 . In case of compound 13, the oxygen of sulfone moiety is perpendicular to the porphyrin plane heme ion with distance $3.44 \AA$ (Figure 2(b)). The phenyl ring of $\mathbf{1 3}$ occupied the hydrophobic region above the heme ring and showed good van der Waals interactions with heme and amino acids Tyr76, Phe78, Phe83, 
<smiles>O=S(=O)(C/C(=N/O)c1ccc(Cl)cc1)c1ccccc1</smiles>

$14 \mathrm{a}$<smiles>COc1ccc(/C(CS(=O)(=O)c2ccccc2)=N/O)cc1</smiles>

$14 b$<smiles>O=S(=O)(C/C(=N/O)c1cccc2ccccc12)c1ccccc1</smiles>

$14 \mathrm{c}$<smiles>Cc1ccc(/C(CS(=O)(=O)c2ccc(C)cc2)=N/O)cc1</smiles>

$14 d$<smiles>NN/N=C(/CS(=O)(=O)c1ccccc1)c1ccc(Cl)cc1</smiles>

$15 \mathrm{a}$<smiles>NN/N=C(\CS(=O)(=O)c1ccccc1)c1ccc2ccccc2c1</smiles>

$15 b$<smiles>Cc1ccc(S(=O)(=O)/C(=C/c2ccc(Cl)cc2)C(=O)c2ccc(F)cc2)cc1</smiles>

$16 \mathrm{a}$<smiles>Cc1ccc(S(=O)(=O)/C(=C/c2ccc(Cl)cc2)C(=O)c2ccc(Cl)cc2)cc1</smiles>

$16 b$

Scheme 2: Structure of compounds 14a-d, 15a, b, and 16a, b [29].

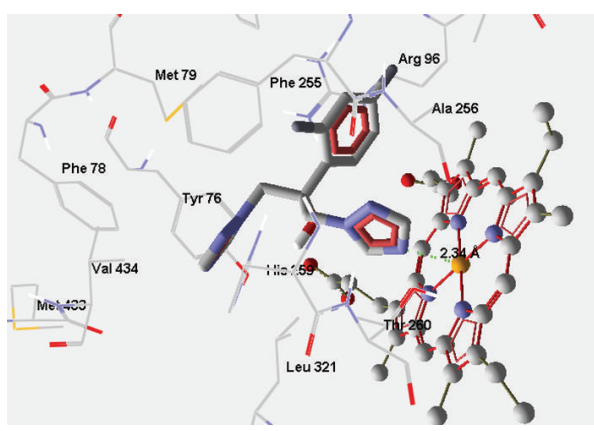

(a)

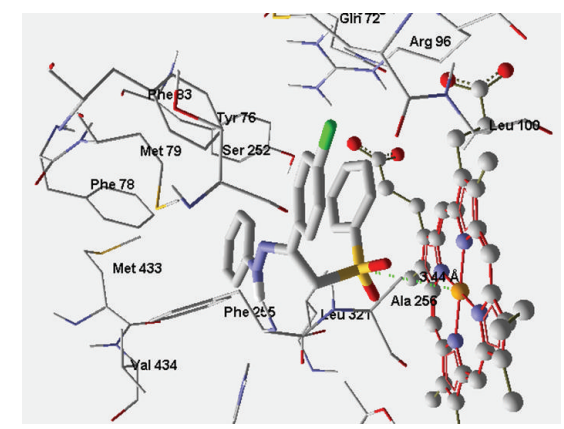

(b)

FIGURE 2: (a) Binding mode of fluconazole into the binding site cytochrome P450 14 $\alpha$-sterol demethylase. (b) Binding mode of 13 into the binding site cytochrome P450 14 $\alpha$-sterol demethylase.

and Phe255. Compound 13 showed excellent MolDock score -165.87 better than that of fluconazole $(-161.29)$ consistent with the results of antifungal activity of $\mathbf{1 3}$ and fluconazole.

It was observed that compound $\mathbf{1 3}$ was oriented in the binding groove of enzyme in such fashion that favors the possibility of $\pi-\pi$ interaction of its three benzene rings with the hydrophobic amino acid residues of the binding site of the enzyme (Figure 3). The latter binding interactions of $\mathbf{1 3}$ are the same as that of fluconazole with binding site of the enzyme (Figure 3). In addition, the sulfone moiety in $\mathbf{1 3}$ occupies the same position of the hydroxyl group in fluconazole as shown in Figure 3.

3.6. Apoptotic Activity Evaluation for Compound 13. It has been shown that loss of phospholipid asymmetry of the plasma membrane is an early event of apoptosis. The annexin$\mathrm{V}$ binds to negatively charged phospholipids, like phosphatidylserine. During apoptosis, the cells react to annexin-V once chromatin condenses but before the plasma membrane loses its ability to exclude DAPI. Hence, by staining cells with a combination of APC annexin-V and DAPI it is possible to detect nonapoptotic live cells, early apoptotic cells, and late apoptotic or necrotic cells. Apoptotic effect of compound 13 against noncancerous human breast epithelial cell line MCF10A showed no effect between the treated $(10 \mu \mathrm{M})$ and the untreated cells (Figure 4).

\section{Conclusion}

In conclusion, 1-(1-(4-chlorophenyl)-2-(phenylsulfonyl)ethylidene)-2-phenylhydrazine (13) was prepared by the reaction of $\beta$-ketosulfone 12 with phenyl hydrazine and its structure was established under the basis of its spectral data. It showed excellent antifungal activities against Candida fungal species. The molecular modeling results showed a similar binding interaction of $\mathbf{1 3}$ and fluconazole in the active site of CYTP-450. The phenylhydrazone moiety plays an important role in the antifungal potentiality of 13. In addition, compound $\mathbf{1 3}$ showed no cytotoxicity against noncancerous cell line MCF10A.

\section{Conflict of Interests}

The authors have declared that there is no conflict of interests. 

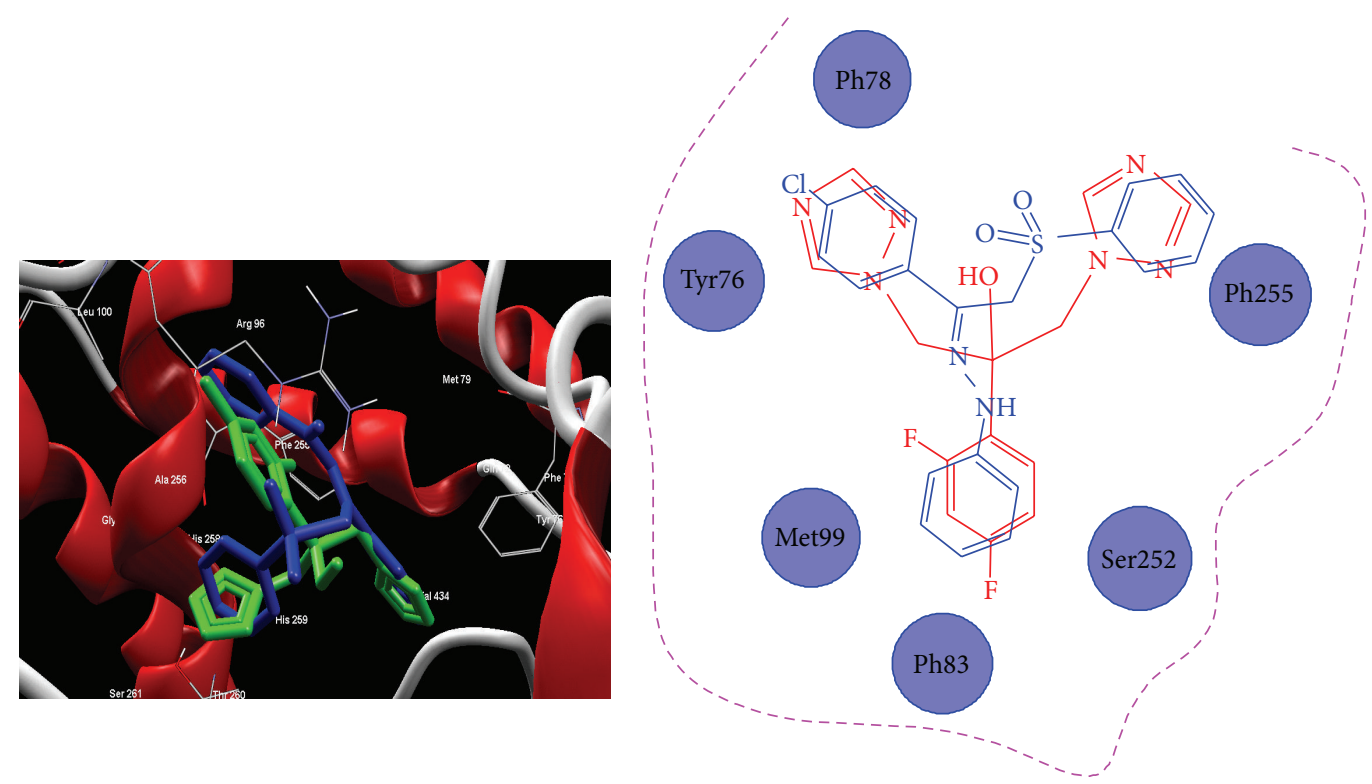

FIGURE 3: Overlay of compound $\mathbf{1 3}$ (blue) and fluconazole (red) showing their 3D and 2D binding interactions in the groove of cytochrome P450 14 $\alpha$-sterol demethylase.
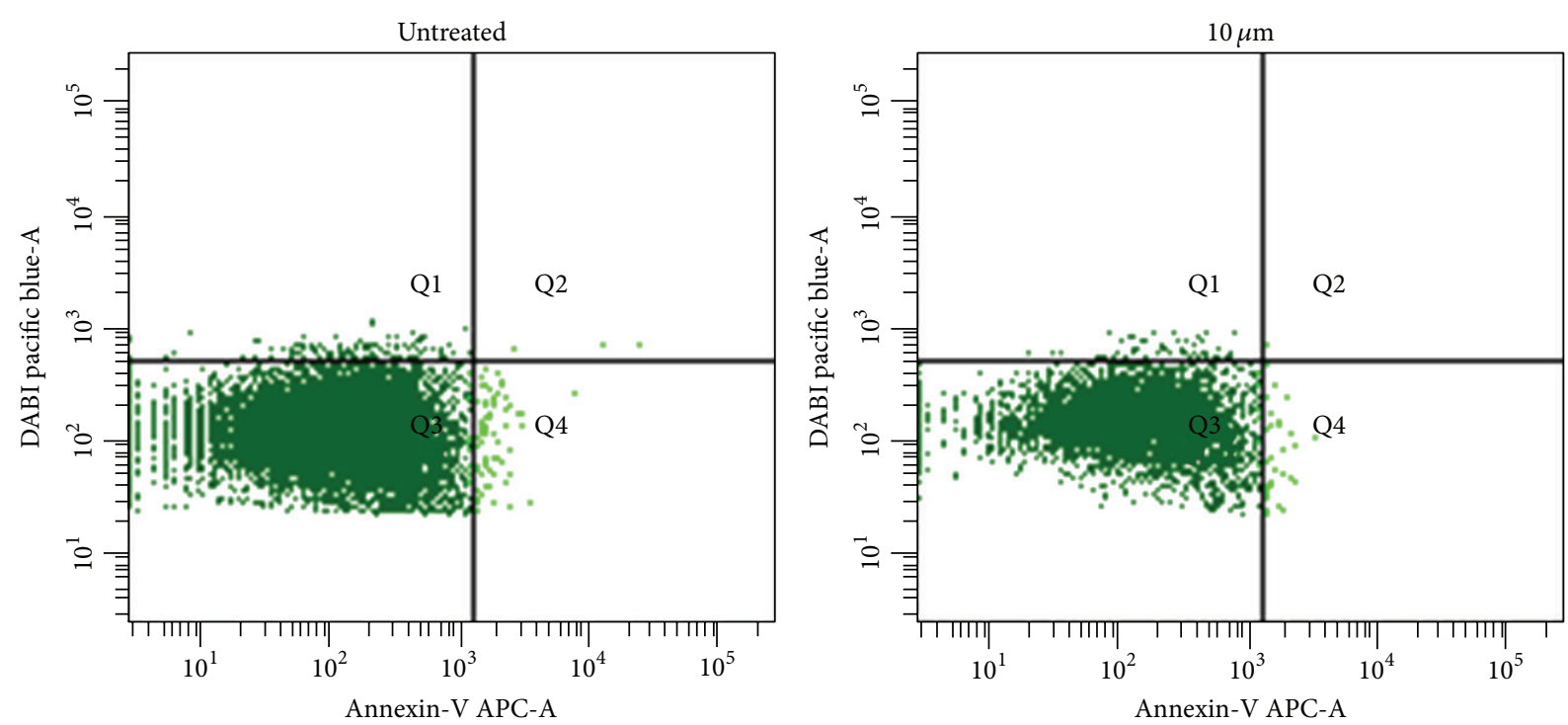

FIGURE 4: Measurement of annexin-V binding by flow cytometry. Apoptotic effects of compound 13 against noncancerous human breast epithelial cell line MCF10A showed no effect between the treated $(10 \mu \mathrm{M})$ and the untreated cells.

\section{Acknowledgment}

The authors would like to extend their sincere appreciation to the Deanship of Scientific Research at King Saud University for its funding of this research through the Research Group Project no. RGP-VPP-321.

\section{References}

[1] T. Segura, A. M. Puga, G. Burillo et al., "Materials with fungibioinspired surface for efficient binding and fungi-sensitive release of antifungal agents," Biomacromolecules, vol. 15, no. 5, pp. 1860-1870, 2014.
[2] M. A. Ghannoum and J. R. Perfect, "History of antifungals," in Antifungal Therapy, chapter 1, pp. 1-10, Informa Healthcare, 2010.

[3] S. Schelenz, "Management of candidiasis in the intensive care unit," The Journal of Antimicrobial Chemotherapy, vol. 61, supplement 1, pp. i31-i34, 2008.

[4] F. Chimenti, B. Bizzarri, A. Bolasco et al., "Synthesis and biological evaluation of novel 2,4-disubstituted-1,3-thiazoles as anti-Candida spp. agents," European Journal of Medicinal Chemistry, vol. 46, no. 1, pp. 378-382, 2011.

[5] D. J. Sheehan, C. A. Hitchcock, and C. M. Sibley, "Current and emerging azole antifungal agents," Clinical Microbiology Reviews, vol. 12, no. 1, pp. 40-79, 1999. 
[6] D. Kong, M.-J. Lee, S. Lin, and E.-S. Kim, "Biosynthesis and pathway engineering of antifungal polyene macrolides in actinomycetes," Journal of Industrial Microbiology and Biotechnology, vol. 40, no. 6, pp. 529-543, 2013.

[7] M. Nowosielski, M. Hoffmann, L. S. Wyrwicz et al., "Detailed mechanism of squalene epoxidase inhibition by terbinafine," Journal of Chemical Information and Modeling, vol. 51, no. 2, pp. 455-462, 2011.

[8] M. B. Kurtz and J. H. Rex, "Glucan synthase inhibitors as antifungal agents," Advances in Protein Chemistry, vol. 56, pp. 423475, 2001.

[9] V. T. Andriole, "Current and future antifungal therapy: new targets for antifungal therapy," International Journal of Antimicrobial Agents, vol. 16, no. 3, pp. 317-321, 2000.

[10] W. M. Holden, J. S. Fites, L. K. Reinert, and L. A. Rollins-Smith, "Nikkomycin $\mathrm{Z}$ is an effective inhibitor of the chytrid fungus linked to global amphibian declines," Fungal Biology, vol. 118, no. 1, pp. 48-60, 2014.

[11] M. Zervos and F. Meunier, "Fluconazole (Diflucan): a review," International Journal of Antimicrobial Agents, vol. 3, no. 3, pp. 147-170, 1993.

[12] C. A. Hitchcock, K. Dickinson, S. B. Brown, E. G. V. Evans, and D. J. Adams, "Interaction of azole antifungal antibiotics with cytochrome P-450-dependent $14 \alpha$-sterol demethylase purified from Candida albicans," Biochemical Journal, vol. 266, no. 2, pp. 475-480, 1990.

[13] Z. A. Kanafani and J. R. Perfect, "Resistance to antifungal agents: mechanisms and clinical impact," Clinical Infectious Diseases, vol. 46, no. 1, pp. 120-128, 2008.

[14] B. A. Stuck, A. Blum, A. E. Hagner, T. Hummel, L. Klimek, and K. Hörmann, "Mometasone furoate nasal spray improves olfactory performance in seasonal allergic rhinitis," Allergy, vol. 58, no. 11, p. 1195, 2003.

[15] A. Legras, A.-M. Bergemer-Fouquet, and A.-P. Jonville-Bera, "Fatal hepatitis with leflunomide and itraconazole," The American Journal of Medicine, vol. 113, no. 4, pp. 352-353, 2002.

[16] N. Somchit, A. R. Norshahida, A. H. Hasiah, A. Zuraini, M. R. Sulaiman, and M. M. Noordin, "Hepatotoxicity induced by antifungal drugs itraconazole and fluconazole in rats: a comparative in vivo study," Human and Experimental Toxicology, vol. 23, no. 11, pp. 519-525, 2004.

[17] J. T. Slama, J. L. Hancock, T. Rho, L. Sambucetti, and K. A. Bachmann, "Influence of some novel $N$-substituted azoles and pyridines on rat hepatic CYP3A activity," Biochemical Pharmacology, vol. 55, no. 11, pp. 1881-1892, 1998.

[18] H. Wulff, M. J. Miller, W. Hänsel, S. Grissmer, M. D. Cahalan, and K. G. Chandy, "Design of a potent and selective inhibitor of the intermediate-conductance $\mathrm{Ca}^{2+}$-activated $\mathrm{K}^{+}$channel, IKCal: a potential immunosuppressant," Proceedings of the National Academy of Sciences of the United States of America, vol. 97, no. 14, pp. 8151-8156, 2000.

[19] M. Plempel, "Experiences, recognitions and questions in azole antimycotics," Japanese Journal of Medical Mycology, vol. 23, no. 1, pp. 17-27, 1982.

[20] R. A. Fromtling, "Overview of medically important antifungal azole derivatives," Clinical Microbiology Reviews, vol. 1, no. 2, pp. 187-217, 1988.

[21] R. L. Dyer, G. J. Ellames, B. J. Hamill, P. W. Manley, and A. M. S. Pope, "Synthesis of (E)-1-(5-chlorothien-2-yl)-2-(1H-imidazol1-yl)ethanone 2,6-dichlorophenylhydrazone hydrochloride, a novel, orally active antifungal agent," Journal of Medicinal Chemistry, vol. 26, no. 3, pp. 442-445, 1983.
[22] J. M. H. Molina, J. Losá, A. M. Brocal, and A. Ventosa, "In vitro activity of cloconazole, sulconazole, butoconazole, isoconazole, fenticonazole, and five other antifungal agents against clinical isolates of Candida albicans and Candida spp," Mycopathologia, vol. 118, no. 1, pp. 15-21, 1992.

[23] A. Ayati, M. Falahati, H. Irannejad, and S. Emami, "Synthesis, in vitro antifungal evaluation and in silico study of 3-azolyl-4chromanone phenylhydrazones," DARU Journal of Pharmaceutical Sciences, vol. 20, no. 1, article 46, 2012.

[24] M. D. Altntop, A. Özdemir, G. Turan-Zitouni et al., "Synthesis and biological evaluation of some hydrazone derivatives as new anticandidal and anticancer agents," European Journal of Medicinal Chemistry, vol. 58, pp. 299-307, 2012.

[25] D. M. Neumann, A. Cammarata, G. Backes, G. E. Palmer, and B. S. Jursic, "Synthesis and antifungal activity of substituted 2,4,6-pyrimidinetrione carbaldehyde hydrazones," Bioorganic \& Medicinal Chemistry, vol. 22, no. 2, pp. 813-826, 2014.

[26] C. Curti, M. Laget, A. O. Carle, A. Gellis, and P. Vanelle, "Rapid synthesis of sulfone derivatives as potential anti-infectious agents," European Journal of Medicinal Chemistry, vol. 42, no. 6, pp. 880-884, 2007.

[27] W. Xu, J. He, M. He et al., "Synthesis and antifungal activity of novel sulfone derivatives containing 1,3,4-oxadiazole moieties," Molecules, vol. 16, no. 11, pp. 9129-9141, 2011.

[28] A. Muralikrishna, B. C. Venkatesh, V. Padmavathi, A. Padmaja, P. Kondaiah, and N. S. Krishna, "Synthesis, antimicrobial and cytotoxic activities of sulfone linked bis heterocycles," European Journal of Medicinal Chemistry, vol. 54, pp. 605-614, 2012.

[29] H. A. Abdel-Aziz, H. A. Ghabbour, M. A. Bhat, and H.-K. Fun, "Microwave-assisted synthesis and characterization of certain oximes, hydrazones and olefins derived from $\beta$-keto sulfones ," Journal of Chemistry, vol. 2014, Article ID 532467, 6 pages, 2014.

[30] A. M. Alafeefy, H. A. Abdel-Aziz, D. Vullo et al., "Inhibition of carbonic anhydrases from the extremophilic bacteria Sulfurihydrogenibium yellostonense (SspCA) and S. azorense (SazCA) with a new series of sulfonamides incorporating aroylhydrazone-, $[1,2,4]$ triazolo $[3,4-b][1,3,4]$ thiadiazinylor 2-(cyanophenylmethylene)-1,3,4-thiadiazol-3(2H)-yl moieties," Bioorganic \& Medicinal Chemistry, vol. 22, pp. 141-147, 2014.

[31] H. A. Abdel-Aziz, T. Elsaman, A. Al-Dhfyan, M. I. Attia, K. A. Al-Rashood, and A.-R. M. Al-Obaid, "Synthesis and anticancer potential of certain novel 2-oxo- $N^{\prime}$-(2-oxoindolin-3ylidene)-2 $H$-chromene-3-carbohydrazides," European Journal of Medicinal Chemistry, vol. 70, pp. 358-363, 2013.

[32] H. A. Abdel-Aziz, P. Ahmad, A. Kadi, K. A. Al-Rashood, H. A. Ghabbour, and H.-K. Fun, "Unexpected ring-opening of 3aroylbenzo[b]furans at room temperature: a new route for the construction of phenol-substituted pyrazoles," Tetrahedron Letters, vol. 54, no. 26, pp. 3424-3426, 2013.

[33] A. M. Alafeefy, S. Isik, N. A. Al-Jaber et al., "Carbonic anhydrase inhibitors. Benzenesulfonamides incorporating cyanoacrylamide moieties strongly inhibit Saccharomyces cerevisiae $\beta$-carbonic anhydrase," Bioorganic and Medicinal Chemistry Letters, vol. 23, no. 12, pp. 3570-3575, 2013.

[34] H. A. Abdel-Aziz, T. Aboul-Fadl, A.-R. M. Al-Obaid, M. Ghazzali, A. Al-Dhfyan, and A. Contini, "Design, synthesis and pharmacophoric model building of novel substituted nicotinic acid hydrazones with potential antiproliferative activity," Archives of Pharmacal Research, vol. 35, no. 9, pp. 1543-1552, 2012. 
[35] H. A. Abdel-Aziz, H. S. A. El-Zahabi, and K. M. Dawood, "Microwave-assisted synthesis and in-vitro anti-tumor activity of 1, 3, 4-triaryl-5-N-arylpyrazole-carboxamides," European Journal of Medicinal Chemistry, vol. 45, pp. 2427-2432, 2010.

[36] H. A. Abdel-Aziz and A. A. I. Mekawey, "Stereoselective synthesis and antimicrobial activity of benzofuran-based (1E)1-(piperidin-1-yl)- $\mathrm{N}_{2}$-arylamidrazones," European Journal of Medicinal Chemistry, vol. 44, no. 12, pp. 4985-4997, 2009.

[37] J. Xiang, M. Ipek, V. Suri et al., " $\beta$-Keto sulfones as inhibitors of $11 \beta$-hydroxysteroid dehydrogenase type I and the mechanism of action," Bioorganic \& Medicinal Chemistry, vol. 15, no. 13, pp. 4396-4405, 2007.

[38] C. Perez, M. Pauli, and P. Bazerque, "An antibiotic assay by the agar well diffusion method," Acta Biologiae et Medicinal Experimentalis, vol. 15, pp. 113-115, 1990.

[39] O. N. Irobi, M. Moo-Young, and W. A. Anderson, "Antimicrobial activity of Annatto (Bixa orellana) extract," Pharmaceutical Biology, vol. 34, no. 2, pp. 87-90, 1996.

[40] A. Urzua, M. Caroli, L. Vasquez, L. Mendoza, M. Wilkens, and E. Tojo, "Antimicrobial study of the resinous exudate and of diterpenoids isolated from Eupatorium salvia (Asteraceae)," Journal of Ethnopharmacology, vol. 62, no. 3, pp. 251-254, 1998.

[41] Molegro Virtual Docker (MVD 2013.6.0.0), Molegro bioinformatics solutions, 2013, (Danish), http://www.molegro.com.

[42] S. M. Kerwin, "ChemBioOffice ultra 2010 suite," Journal of the American Chemical Society, vol. 132, no. 7, pp. 2466-2467, 2010.

[43] Marvinsketch, "version 6.1.0, Chemaxon company cheminformatics technology products services," 2013, http://www.chemaxon.com/.

[44] E. Banfi, G. Scialino, D. Zampieri et al., "Antifungal and antimycobacterial activity of new imidazole and triazole derivatives. A combined experimental and computational approach," Journal of Antimicrobial Chemotherapy, vol. 58, no. 1, pp. 76-84, 2006.

[45] A. A. O. Sarhan, A. Al-Dhfyan, M. A. Al-Mozaini, C. N. Adra, and T. Aboul-Fadl, "Cell cycle disruption and apoptotic activity of 3-aminothiazolo[3,2-a]benzimidazole-2-carbonitrile and its homologues," European Journal of Medicinal Chemistry, vol. 45, no. 6, pp. 2689-2694, 2010.

[46] L. M. Podust, T. L. Poulos, and M. R. Waterman, "Crystal structure of cytochrome P450 14 $\alpha$-sterol demethylase (CYP51) from Mycobacterium tuberculosis in complex with azole inhibitors," Proceedings of the National Academy of Sciences of the United States of America, vol. 98, no. 6, pp. 3068-3073, 2001. 

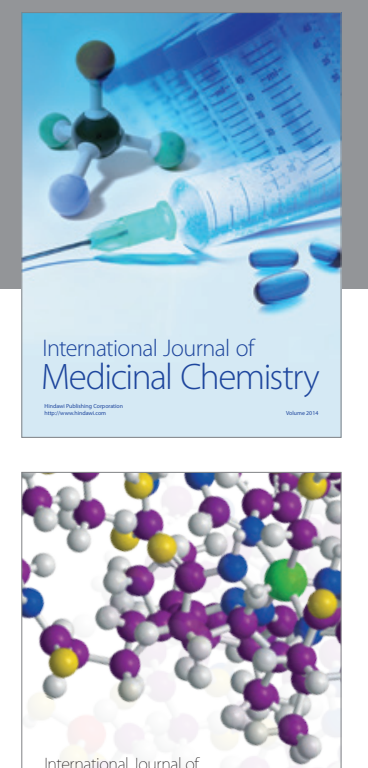

\section{Carbohydrate} Chemistry

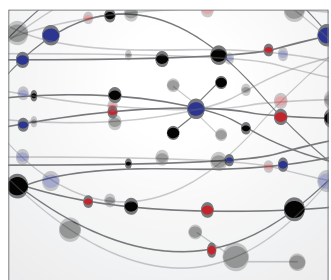

The Scientific World Journal
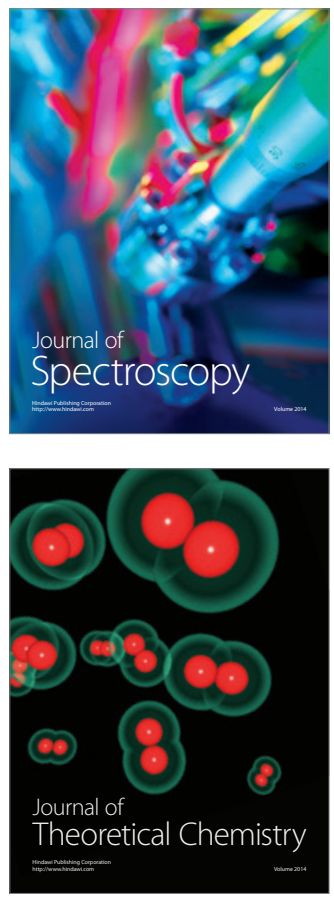
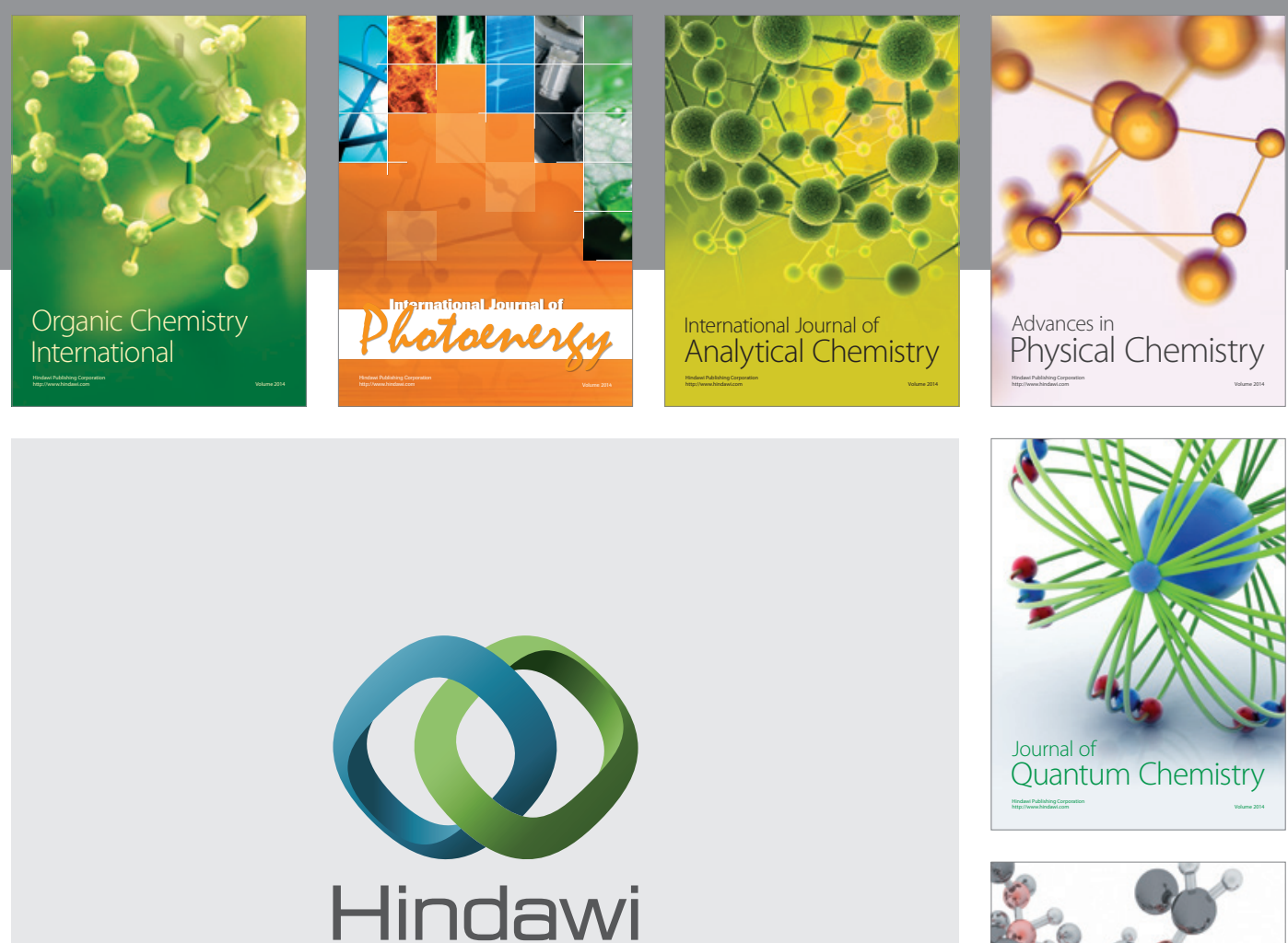

Submit your manuscripts at

http://www.hindawi.com

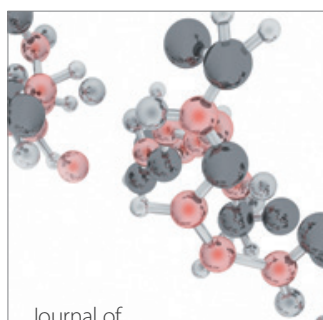

Analytical Methods

in Chemistry

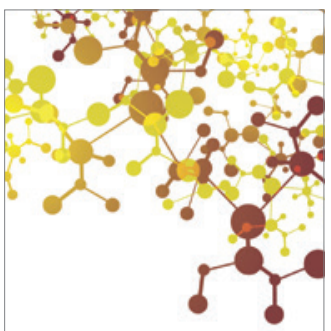

Journal of

Applied Chemistry

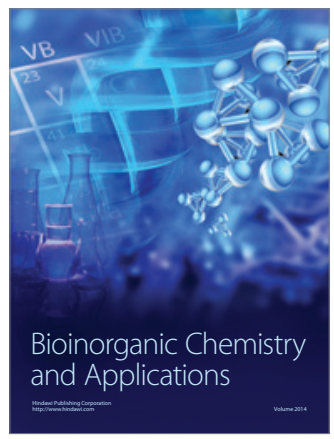

Inorganic Chemistry
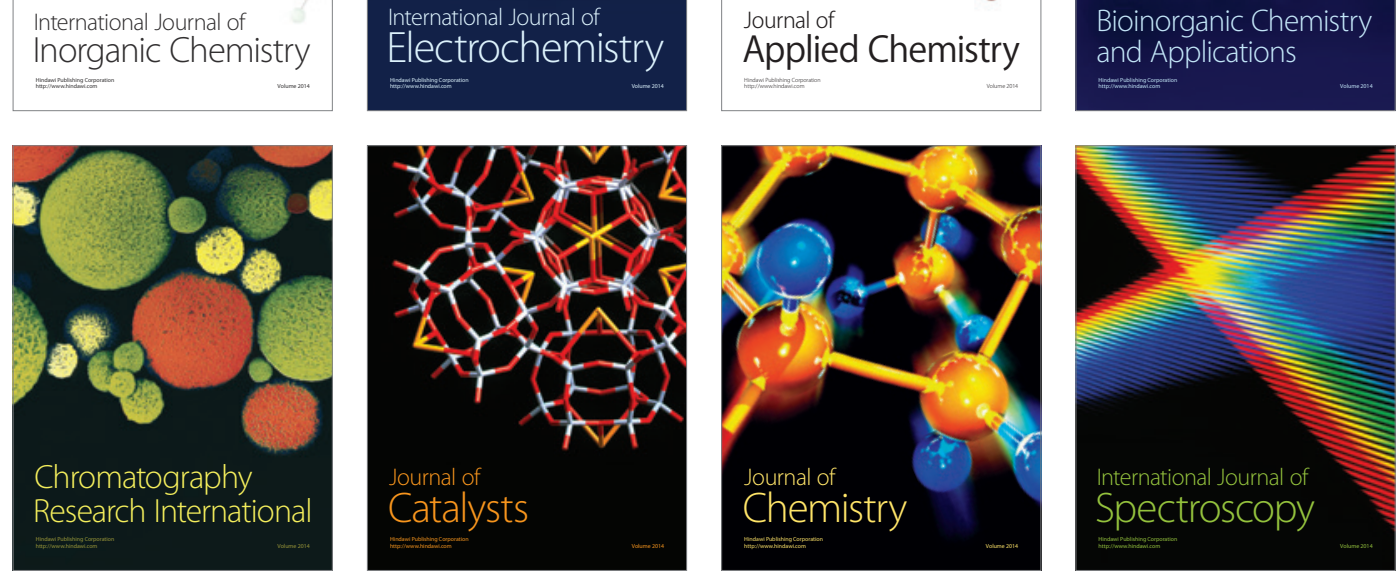